\title{
PENERAPAN METODE CERTAINTY FACTOR UNTUK DIAGNOSA PENYAKIT TANAMAN BUAH NAGA
}

\author{
Apri Riyawan', Sita Muharni', M. Adie Syaputra ${ }^{3}$ \\ ${ }^{1}$ Apri Riyawan, STMIK Dharma Wacana Metro, apririyawan@gmail.com \\ ${ }^{2}$ Sita Muharni STMIK Dharma Wacana Metro, sita.stmikdharmawacana@gmail.com \\ ${ }^{3}$ M. Adie Syaputra, STMIK Dharma Wacana Metro, m4adie@gmail.com \\ Jalan Kenangan No.3 Mulyojati Kota Metro \\ Email : apririyawan@gmail.com
}

\begin{abstract}
ABSTRAK
Tanaman buah naga merupakan tamanan yang mempunyai beberapa penyakit dan memiliki gejala yang hampir sama. Namun jika diamati lebih lanjut beberapa penyakit bisa dibedakan berdasar gejala lain yang mengikuti. Pendiagnosaan merupakan dugaan penyakit yang paling mendekati kebenaran berdasarkan gejala yang ditimbulkan dan pertimbangan secara tepat. Metode Certainty Factor merupakan Metode yang didasarkan pada nilai bobot $C F$ gejala terhadap suatu penyakit dan nilai interpretasi keprcayaan yang di berikan petani terhadap gejala yang timbul. Pada penelitian sebelumnya Metode certainty factor mempunyai nilai akurasi 94,6\% dalam perhitungan diagnosanya. Perhitungan metode certainty factor dipengaruhi nilai bobot dan nilai interprestasi kepercayaan user terhadap objek. Penerapan metode Certainty factor diharapkan digunakan untuk mendiagnosa penyakit pada tanaman buah naga sehungga didapatkan nilai persentase kemungkinan jenis penyakitnya..
\end{abstract}

Kata Kunci : Certainty Factor, Buah Naga

\section{PENDAHULUAN}

\subsection{Latar Belakang Masalah}

Pendiagnosaan buah naga berdasarkan dari beberapa gejala yang ditimbulkan seperti layu, karat merah, busuk batang, batang kuning dan yang lainnya (Ari Wibowo,2018). Dari gejala yang ditimbulkan terbagi menjadi gejala utama atau gejala yang dominan dan gejala yang mengikuti atau gejala sekuler. Pendiagnosaan dilakukan dengan mempertimbangkan gejala yang muncul dengan menentukan mana yang paling dominan dan mana yang tidak dominan. Tetapi terkadang dalam praktiknya sering terjadi kesalahan dalam menentukan gejala yang dominan. Dengan masalah seperti itu penerepan metode certainity faktor mungkin bisa menjadi altenatif dari pakar. Metode certainity factor akan menghitung dari hasil bobot gejala dari basis pengetahuan seorang pakar kemuadian juga akan menghitung dari nilai interprestasi yang sudah ditentukan berdasarkan jawaban dari petani yang melihat secara langsung gejala yang timbul.(Arfifin,
2017) Informasi tentang penanganan penyakit pada tanaman buah naga. Pada penentuan obat pembasmi jamur atau bakteri ini terkadang para petani kurang tepat dalam penerapan sesuai penyakit yang menyerang. Hal ini dapat berdampak pada kualitas hasil panen dan tingkat produktifitas dari komoditi buah naga tersebut. Bahkan jika terjadi keterlambatan atau tidak segera diatasi sesuai dengan kriteria penyakitnya akan terjadi kematian pada tanaman buah naga tersebut. Keterbatasan informasi juga menjadi salah satu hambatan yang mengakibatkan terjadi penanganan pada lahan yang terkena penyakit, hal ini dapat mengakibatkan meluasnya penyakit yang menyerang lahan tersebut ke lahan yang lain. Diperlukan sebuah sistem yang dapat memudahkan masyarakat terutama petani untuk mengetahui secara dini atau mendiagnosis penyakit tersebut dengan tepat serta saran penanggulangannya. Metode 
certainty factor yang merupakan salah satu tehnik untuk mengatasi ketidakpastian dalam mengambil keputusan. Metode "certainty factor diterapakan karena metode ini dalam proses penentuan diagnosa penyakit dan hasil

\subsection{Metode Certainty Factor}

Metode Certainty Factor adalah faktor kepastian, metode ini digunakan menyatakan kepastian dalam sebuah hipotesis atau fakta yang berdasarkan penilaian pakar dan kejadian dilapangan. Metode ini digaunakan untuk mengambil keputusan dalam menghadapi ketidakpastian sebuah kenyataan. Besarnya kepastian dalam metode ini untuk menilai besarnya kepastian dari ahli pakar terhadap suatu kumpulan data,(Sutojo,2011) maka konsep ini dijabarkan kedalam suatu rumusan dasar sebagai berikut :

\section{$\mathrm{CF}[\mathrm{H}, \mathrm{E}]=\mathrm{MB}[\mathrm{H}, \mathrm{E}]-\mathrm{MD}[\mathrm{H}, \mathrm{E}]$}

Keterangan :

CF :"Certainty-Factor"'(Faktor

Kepastian) dalam hipotesa

$\mathrm{H}$ yang dipengaruhi oleh fakta $\mathrm{E}$.

$\mathbf{M B}(\mathbf{H}, \mathbf{E}) \quad$ : "Besaran Kepercayaan hipotesa(dugaan) $\mathrm{H}$, jika diberikan "Evidence" $\mathrm{E}$ antara 0 dan 1."

$\operatorname{MD}(\mathbf{H}, \mathbf{E}) \quad$ : "Besaran Kepercayaan "Evidence" $\mathrm{H}$, jika diberikan Evidence $\mathrm{E}$ antara 1 dan $0 . "$

\section{HASIL DAN PEMBAHASAN}

Hasil dari pengumpulan data gejala, penyakit dan rule base (dapat dilihat pada tabel 1, tabel 2 dan tabel 3) didapatkan dari seorang pakar, dapat dibuat bagan aturan penyakit tanaman buah naga yang dapat dilihat pada gambar 3. Tabel dibawah ini berisikan kode, nama gejala dan nilai bobot pada tanaman buah naga. penerapan adalah persentase".(Khairina,2018). Persentase sistem disini merupakan tingkat akurasi penentuan penyakit yang menjangkit tananaman buah naga.

1. Kaidah aturan tunggal

"CF $[\mathrm{H}, \mathrm{E}]=\mathrm{CF}[\mathrm{H}] * \mathrm{CF}[\mathrm{E}]$ "

Dimana

"CF $[\mathrm{H}]$ " = Besaran kepercayaan pengguna /petani

"CF [E]" = Besaran kepercayaaan pakar /ahli

CF combine $\mathrm{CF}[\mathrm{H}, \mathrm{E}] \mathrm{l}=\mathrm{CF}[\mathrm{H}, \mathrm{E} 1]+\mathrm{CF}[\mathrm{H}, \mathrm{E} 2] *(1-\mathrm{CF}[\mathrm{H}, \mathrm{E} 1])$

$\mathrm{CF}$ combine $\mathrm{CF}[\mathrm{H}, \mathrm{E}] \mathrm{lld}=\mathrm{CF}[\mathrm{H}, \mathrm{E}] \mathrm{old} 1+\mathrm{CF}[\mathrm{H}, \mathrm{E}]\}^{*}(1-\mathrm{CF}[\mathrm{H}, \mathrm{E}] \mathrm{ldd} \mathrm{l})$

Pejumlahan besaran kepercayaan dan besaran ketidakpercayaan dalam angka dari hasil mempunyai dua fungsi yaitu pertama adalah fungsi kepastian digunakan sebagai tingkat hipotesa dalam urutan kepentingan. Sebagai contoh sebauh tanaman memiliki gejala tertentu yang manyarankan beberapa kemungkinan penyakit kemudian penyakit dengan $\mathrm{CF}$ tertinggi menjadi urutan pertama dalam pengurutan perhitungan

Tabel 1 Interprestasi Nilai Certainty Factor

\begin{tabular}{|r|c|r|}
\hline No & Keterangan & Bobot \\
\hline 1 & Hampir Mungkin & 0,2 \\
\hline 2 & Mungkin & 0,4 \\
\hline 3 & Kemungkinan Besar & 0,6 \\
\hline 4 & Hampir Pasti & 0,8 \\
\hline 5 & Pasti Ya & 1,0 \\
\hline
\end{tabular}




\begin{tabular}{|c|l|r|}
\hline Kode & \multicolumn{1}{|c|}{ Gejala } & Bobot \\
\hline G1 & $\begin{array}{c}\text { Busuk berwarna coklat dan tidak } \\
\text { lunak dibatang }\end{array}$ & 0.8 \\
\hline G2 & Bercak coklat kehitaman & 0.6 \\
\hline G3 & Permukaan batang rusak dan kasar & 0.2 \\
\hline G4 & Batang kuning & 0.6 \\
\hline G5 & Layu & 1.0 \\
\hline G6 & Bintik merah pada tengah mosaik & 0.8 \\
\hline G7 & Busuk hitam pada batang & 0.4 \\
\hline G8 & Bercak merah pada batang & 0.8 \\
\hline
\end{tabular}

Tabel 2 Gejala Penyakit Tanaman Buah Naga

Tabel 4 Kondisi Tanaman Buah Naga

\begin{tabular}{|c|c|c|c|c|c|c|}
\hline \multirow{2}{*}{$\begin{array}{l}\text { Kode } \\
\text { Gejala }\end{array}$} & \multirow{2}{*}{ Nama Gejala } & \multicolumn{5}{|c|}{ Kode Penyakit } \\
\hline & & $\mathrm{P} 01$ & P02 & P03 & P04 & P05 \\
\hline G1 & $\begin{array}{l}\text { Busuk berwarna coklat dan tidak lunak } \\
\text { dibatang }\end{array}$ & & & & & \\
\hline $\mathrm{G} 2$ & Bercak coklat kehitaman & & & & & \\
\hline G3 & Permukaan batang rusak dan kasar & & & & & \\
\hline G4 & Batang kuning & & & & & \\
\hline G5 & Layu & & & & & \\
\hline G6 & Bintik merah pada tengah mosaik & & & & & \\
\hline G7 & Busuk hitam pada batang & & & & & \\
\hline G8 & Bercak merah pada batang & & & & & \\
\hline
\end{tabular}

\section{Contoh Kasus :}

Tanaman buah naga Pak Joko terjangkit penyakit dengan gejala bercak coklat kehitaman, batang kuning, dan bintik merah pada tengah mosaik. Agar dapat mengetahui penyakit yang menyerang tanaman buah naga Pak Joko dan mengetahui nilai "certainty factor" nya dapat ditentukan dengan rule yang berkaitan dengan gejala-gejala pada tanaman buah naga tersebut.

Perhitungan:

1. Pemecahan rule dengan premis (ciri) majemuk menjadi rule dengan premis tunggal.

a. Premis Pertama

IF Bercak coklat kehitaman THEN

NOT Karat Merah

IF Batang Kuning THEN Karat Merah

IF Bintik Merah ditengah Mosaik

THEN Karat Merah b. Premis Kedua

IF Bercak coklat kehitaman THEN

NOT Layu Fusariuim

IF Batang Kuning THEN Layu

Fusarium

IF Bintik Merah ditengah Mosaik

THEN Layu Fusarium

c. Premis Ketiga

IF Bercak coklat kehitaman THEN

Antraknosa

IF Batang Kuning THEN NOT

Antraknosa

IF Bintik Merah ditengah Mosaik

THEN NOT Antraknosa

d. Premis Keempat

IF Bercak coklat kehitaman THEN

NOT Busuk Batang

IF Batang Kuning THEN Busuk

Batang

IF Bintik Merah ditengah Mosaik

THEN NOT Busuk Batang

2. Menentukan Nilai Certainty Factor Pakar masing-masing Premis(ciri)

a. Premis Pertama

\begin{tabular}{|l|l|l|}
\hline Kode & Nama Gejala & CF Rule \\
\hline G2 & Bercak coklat kehitaman & 0.0 \\
\hline G4 & Batang kuning & 0.6 \\
\hline G6 & Bintik Merah ditengah Mosaik & 0.8 \\
\hline
\end{tabular}

b. Premis Kedua

\begin{tabular}{|l|l|l|}
\hline Kode & Nama Gejala & CF Rule \\
\hline G2 & Bercak coklat kehitaman & 0.0 \\
\hline G4 & Batang kuning & 0.6 \\
\hline G6 & Bintik Merah ditengah Mosaik & 0.8 \\
\hline
\end{tabular}

c. Premis Ketiga

\begin{tabular}{|l|l|l|}
\hline Kode & Nama Gejala & CF Rule \\
\hline G2 & Bercak coklat kehitaman & 0.6 \\
\hline G4 & Batang kuning & 0.0 \\
\hline G6 & Bintik Merah ditengah Mosaik & 0.0 \\
\hline
\end{tabular}

d. Premis Keempat

\begin{tabular}{|l|l|l|}
\hline Kode & Nama Gejala & CF Rule \\
\hline G2 & Bercak coklat kehitaman & 0.0 \\
\hline G4 & Batang kuning & 0.6 \\
\hline G6 & Bintik Merah ditengah Mosaik & 0.0 \\
\hline
\end{tabular}


$=0.92$

$\mathbf{C F}_{\text {old2 }}=0.92$

4. Dengan Certainty Factor User menggunakan persamaan

Rumus : $\mathrm{CF}(\mathrm{H}, \mathrm{E})=\mathrm{CF}[\mathrm{E}] * \mathrm{CF}[$ rule $]$

a. Premis Pertama

冉

\begin{tabular}{|l|l|}
\hline $\mathrm{CF}$ & $\mathrm{CF}$ User \\
\hline 1 & 1.0 \\
\hline 2 & 1.0 \\
\hline 3 & 1.0 \\
$\mathrm{x}$ \\
$\mathrm{x}$ \\
$\mathrm{x}$
\end{tabular}

b. Premis Kedua

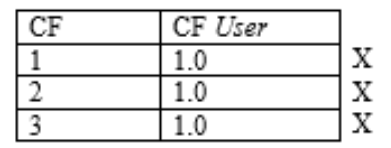

\begin{tabular}{|l|l|}
\hline CF Rule & CF $(\mathrm{H}, \mathrm{E})$ \\
\hline 0.0 & 0.0 \\
\hline 0.8 & 0.6 \\
\hline 0.6 & 0.8 \\
\hline
\end{tabular}

c. Premis Ketiga

\begin{tabular}{|l|l|}
\hline CF & CF User \\
\hline 1 & 1.0 \\
\hline 2 & 1.0 \\
\hline 3 & 1.0 \\
\hline
\end{tabular}

\begin{tabular}{|l|l|}
\hline CF Rule & CF $(\mathrm{H}, \mathrm{E})$ \\
\hline 0.0 & 0.6 \\
\hline 0.8 & 0.0 \\
\hline 0.6 & 0.0 \\
\hline
\end{tabular}

d. Premis Keempat

\begin{tabular}{|l|l|}
\hline $\mathrm{CF}$ & CF User \\
\hline 1 & 1.0 \\
\hline 2 & 1.0 \\
\hline 3 & 1.0 \\
$\mathrm{x}$ \\
$\mathrm{x}$ \\
$\mathrm{y}$
\end{tabular}

\begin{tabular}{|l|l|}
\hline CF Rule & CF $(\mathrm{H}, \mathrm{E})$ \\
\hline 0.0 & 0.0 \\
\hline 0.8 & 0.6 \\
\hline 0.6 & 0.0 \\
\hline
\end{tabular}

3. Penentuan Certainty Factor User

\begin{tabular}{|l|l|l|l|}
\hline Kode & Nama Gejala & Jawaban & CF Rule \\
\hline G2 & Batang Kuning & Pasti & 1.0 \\
\hline G4 & Layu & Pasti & 1.0 \\
\hline G6 & Bintik Merah ditengah Mosaik & Pasti & 1.0 \\
\hline
\end{tabular}

a. Premis Pertama

$$
\begin{aligned}
& \text { Rumus :" } \mathrm{CF} \text { combine1 }(\mathrm{CF} \text { gejala1 }, \mathrm{CF} \text { gejala2 })= \\
& \quad \mathrm{CF} \text { gejala1 }+\mathrm{CF} \text { gejala2 } *\left(1-\mathrm{CF}_{\text {gejala } 1}\right) " \\
& =0.0+0.6 *(1-0 .) \\
& =0.0+0.6 \\
& \mathbf{C F}_{\text {old } 1}=0.6 \\
& \text { "CF } \mathrm{CF}_{\text {combine2 } 2}\left(\mathrm{CF}_{\text {old } 1}, \mathrm{CF}_{\text {gejala3 }}\right)=\mathrm{CF}_{\text {old } 1}+\mathrm{CF} \\
& \text { gejala3 } *\left(1-\mathrm{CF}_{\text {old } 1) "}\right) \\
& =0.6+0.8 *(1-0.6) \\
& =0.6+0.32
\end{aligned}
$$

b. Premis Kedua

Rumus :" $\mathrm{CF}_{\text {combine1 }}\left(\mathrm{CF}_{\text {gejala1 }}, \mathrm{CF}\right.$ gejala2 $)=$

$\mathrm{CF}$ gejala1 $+\mathrm{CF}$ gejala2 $*\left(1-\mathrm{CF}_{\text {gejala1 } 1)}\right.$ "

$=0.0+0.6 *(1-0$.

$=0.0+0.6$

$\mathbf{C F}_{\text {old1 }}=0.6$

$\mathrm{CF}_{\text {combine2 } ~}\left(\mathrm{CF}\right.$ old $\left.1, \mathrm{CF}_{\text {gejala3 }}\right)=\mathrm{CF}$ old $1+\mathrm{CF}$ gejala3 $*\left(1-\mathrm{CF}_{\text {old } 1}\right) "$

$=0.6+0.8 *(1-0.6)$

$=0.6+0.30$

$=0.90$

$\mathbf{C F}_{\text {old2 }}=0.90$

c. Premis Ketiga

Rumus : " $\mathrm{CF}_{\text {combine1 }}(\mathrm{CF}$ gejala1, $\mathrm{CF}$ gejala2)

$=\mathrm{CF}$ gejala1 $+\mathrm{CF}$ gejala2 $*\left(1-\mathrm{CF}_{\text {gejala } 1)}\right)$ "

$=0.6+0.0 *(1-0.6)$

$=0.6+0.0$

$\mathbf{C F}_{\text {old1 }}=0.6$

Untuk $\mathrm{CF}_{\text {gejala3 }}$ bernilai $=0$ yang tidak akan merubah hasil

d. Premis Ketiga

Rumus : " $\mathrm{CF}$ combine1 $(\mathrm{CF}$ gejala1, $\mathrm{CF}$

gejala 2$)=\mathrm{CF}$ gejala $+\mathrm{CF}$ gejala $2 *(1-$

$\left.\mathrm{CF}_{\text {gejala1 }}\right)$ "

$$
=0.0+0.6 *(1-0 .)
$$$$
=0.0+0.6
$$$$
\mathbf{C F}_{\text {old1 }}=0.6
$$

Untuk $\mathrm{CF}_{\text {gejala3 }}$ bernilai $=0$ yang tidak akan merubah hasil.

\section{Kesimpulan :}

\begin{tabular}{|l|l|l|c|}
\hline \multicolumn{1}{|c|}{ Premis } & Hasil & Persentase & Penyakit \\
\hline Pertama & 0.92 & $92 \%$ & Karat Merah \\
\hline Kedua & 0.90 & $90 \%$ & $\begin{array}{c}\text { Layu } \\
\text { Fusarium }\end{array}$ \\
\hline Ketiga & 0.60 & $60 \%$ & Antraknosa \\
\hline Keempat & 0.60 & $60 \%$ & $\begin{array}{c}\text { Busuk } \\
\text { Batang }\end{array}$ \\
\hline
\end{tabular}

Dari tabel diatas dapat perhitungan dari premis pertama mendapatkan persentase $92 \%$ dengan penyakit Karat Merah. 


\subsection{KESIMPULAN DAN SARAN}

\section{A. Kesimpulan}

Berdasarkan penelitian dan hasil pengujian metode ini dapat disimpulkan sebagai berikut :

1. Dengan menggunakan metode certainty factor dalam perhitungan untuk mendiagnosa penyakit buah naga didapatkan hasil berupa persentase nilai dari kemungkinan penyakit yang menyerang tanaman buah naga.

2. Certainty factor dapat dijadikan altenatif dalam melakukan perhitungan terhadap diagnosa penyakit pada tanaman buah naga.

\section{B. Saran}

1. Pengembangan disarankan dapat dilakukan dengan menggunakan metode yang lainya.

2. Diharapkan dapat dipergunakan untuk masyarakat pada umumnya.

\section{DAFTAR PUSTAKA}

Andi Arhami, M. (2015). Konsep Dasar Sistem Pakar. Yogyakarta: Erlangga.

Ani Widiastuti, W. A. (2012). UJI

EFEKTIVITAS PESTISIDA

TERHADAP BEBERAPA PATOGEN PENYEBAB PENYAKIT. Jurnal

Perlindungan Tanaman Indonesia, , Vol. 17, No. 2, 2011: 73-76.

Anton, S. (2009). Sistem Pakar Diagnosa Penyakit Tanaman Padi berbasis Web Dengan Fordward dan Backward Chaining, Jurnal Telkomnika Vol. 7, Yogyakarta.

Arfifin, M., Slamin, \& Yuliaretni, W. E. (2017). Penerapan Metode Certainty Factor Untuk Sistem Pakar Diagnosis
Hama Dan Penyakit Pada Tanaman

Tembakau. Berkala Saintek, V (1) :2128.

Aryasa, K. (2018). Sistem Pakar

DiagnosaPenyakit Tanaman

Agribisnis. Jurnal Sistem Informasi dan Teknologi, Vol.7, No.1.

Hardjadinata, I. S. (2012). Budidaya Buah Naga. Banyuwangi: Permata Buku.

Hariyanto, R., \& Sa`dyah, K. (Januari 2018). Sistem Pakar Diagnosis Penyakit \& Hama Pada Tanaman Tebu Mengunakan Metode Certainty Factor. Jointecs Vol.3, No.1.

Khairina Eka Setyaputri, A. S. (2018).

Analisis Metode Certainty Factor pada Sistem Pakar . Jurnal Teknik Elektro, Vol. 10 No. 1.

Muhammad Salfudin, U. R. (2017). Sistem

Pakar Menggunakan Metode

Backward dan Fordward Chaining.

Communication and Innovative

Technology Journal, Vol.10 No.1.

Puspita, I. (2015). Perancangan Aplikasi

Sistem Pakar untuk Mendiagnosa Penyakit padaTanaman Buah Naga berbasis Web dengan Metode Forward Chaining, STIMIK AMIKOM.

Rudi Hariyanto, K. S. (2018). Communication and Innovative Technology Journal -. Jointecs, Vol.3 No.1.

Sihotang, H. T. (2014). SISTEM PAKAR MENDIAGNOSA PENYAKIT KOLESTEROL PADA REMAJA . Jurnal Mantik Penusa, Vol 15 No 1 Juni 2014 ISSN 2088-3943. 
Sutojo, T. M. (2011). Kecerdasan Buatan.

Yogyakarta: Erlangga. 